\title{
Editorial
}

\section{Bicycle injuries and injury prevention}

\author{
I. B. Pless, CM, MD, FRCPC
}

In 1989, long before this journal added injuries to its title, it published two papers on childhood injuries and I was asked to write an editorial for this occasion. I chose the title "Challenges for Injury Prevention: Two Neglected Aspects", because I thought the papers neglected to mention the inadequacy of injury statistics (at the time there were no emergency department data) and also failed to emphasize the public health importance of childhood injuries. It is instructive, therefore, to compare this issue's offerings with how matters stood nearly 25 years ago and see what progress we've made.

Papers in this and the previous issue of this journal discuss bicycle safety in general and helmet use in particular. Although this is a somewhat narrow focus, it serves as one indicator of how the field has evolved and what remains to be done to improve both the science and policy in this domain.

The literature (and media) is still riddled with anti-bike helmet and anti-helmet legislation papers. The arguments range from "helmets are ineffective when hit by a car" (this is only partly true because at least one paper shows that even in crashes they provide some protection ${ }^{2}$ ) to "they send the wrong signal that bicycling is dangerous"' (this is false; bicycling can be dangerous). ${ }^{3}$ Moreover, there is no strong evidence that wearing a helmet makes cycling more dangerous, as some suggest. For example, one intriguing report ${ }^{4}$ that later work discredited ${ }^{5,6}$ proposed that helmets encourage drivers to ride closer to bicyclists. Many of the anti-legislation papers rely heavily on one Australian study $^{7}$ for evidence that legislation decreases ridership (but overlook many other studies, for example, a long-term study of bicycle-related head injuries conducted by Olivier et al. ${ }^{8}$ that convincingly demonstrate no significant postlegislation decline). The anti-legislators also argue that less cycling leads to more obesity and other ill effects on our health but no papers provide good evidence in support of this argument.

Neither the original Australian report ${ }^{7}$ nor any others have told us how long the decline in riding (if any) persisted following legislation. Nor has anyone provided physiological data to support the assertion that any such decline actually decreases fitness or increases obesity rates. ${ }^{9}$ Even if true (which I doubt because most bicyclists do not ride long enough or fast enough to burn many calories), this does not mean that helmet legislation is not in the interest of public health. The cost-economical, physical and psychological-of a single serious head injury is significant. In this light, the importance of preventive action, including legislation requiring helmet use, becomes obvious. I am not suggesting that the problem of obesity among Canadian children is trivial; it is not. But in the context of the helmet legislation debate, the figures simply do not add up.

A recent Canadian judgment awarded a family $\$ 3$ million for a child who had been severely injured when skiing. ${ }^{10}$ And, during just one follow-up year, the medical costs of patients hospitalized with a traumatic brain injury (TBI) in Ontario were $\$ 120.7$ million. ${ }^{11}$ Miller, ${ }^{12,13}$ a leading health economist in the United States, and his associates consistently show the enormous cost benefit of wearing a helmet. One such study estimated the total cost of TBI, including medical care, work loss and change in quality of life, at $\$ 206$ billion (USD) for 1.3 million cases. ${ }^{12}$ For severe (Abbreviated Injury Score [AIS] 4-6) head injuries in all age groups, the average cost per patient was over \$1 million (USD), and for the very severe (AIS 6), \$3.3 million (USD); even for child cyclists with any TBI (severe and less severe), the average cost was $\$ 62000$ (USD). ${ }^{13}$

And these are just the dollar costs. The emotional cost to child and family are also staggering. In contrast, the cost of obesity as a direct consequence of reduced bicycling - the context in which this issue is being debated-is not known, but it is not likely to approach the numbers given by the head injury studies. To arrive at a figure that is remotely accurate, we would need to know how many children stopped cycling because of helmet laws (the data so far are wholly inconsistent); how many became obese as a direct consequence of not cycling; and how many of these developed type 2 diabetes or heart disease. Then we would need to estimate the dollar costs of treating these illnesses. To the best of my knowledge, no one has published any such estimates.

Nor it is just the serious head injuries that are important to public health. My experience of being "doored" (see photo) convinces me that, had I not been wearing a helmet, my head injury would have been far more serious. Dooring, along with other fairly common events such as falls as a result of potholes or collisions with unwary pedestrians, fully convinces me that helmets are essential even when car crashes are set aside. With this in mind, let's examine what the reports in the previous and current issues of Chronic Diseases and Injuries in Canada add to the debate. 
Lindsay and Brussoni ${ }^{14}$ discuss pediatric injuries related to all non-motorized wheeled activities, that is, scooters, skateboards and in-line skates as well as bicycles. They use data from the Canadian Hospitals Injury Reporting and Prevention Program (CHIRPP $)^{15}$ to generate a portrait of the way children can get injured when using these types of "wheels." Most were injured while cycling, most were boys, and most injuries were the result of falls. So far the findings are not remarkable. However, almost 10\% had a head injury, and these were especially common among cyclists. Of note, the authors found that "patients ... in jurisdictions where helmet use is mandated had 2.12 greater odds of helmet use and 0.86 lesser odds of head injury compared with those without helmet laws."14p74 I agree with their conclusion that the small number of patients who used helmets or other protective gear points to an area that needs intervention. ${ }^{14}$ Clearly, that intervention must include efforts to persuade provinces without helmet legislation to reconsider this decision in much the same way as all provinces now view seatbelts.

The study by Romanow et al. ${ }^{16}$ from the previous issue of this journal is a step up the evidence ladder because it employs a case control design. The authors examined the effect of bicycle helmet fit and position on head and facial injury risk. Not surprisingly, they found that poor fit or poor positioning increased the odds of a head injury by as much as six times. Although at one level this finding simply affirms the obvious, it is important because poor fit and poor wearing undoubtedly confound the results of most earlier studies of helmet effectiveness. Unless fit was taken into account, these studies will have reported large underestimates of effectiveness. It is much like trying to examine seat belt effectiveness without taking into consideration whether belts were properly fitted or secured.

Finally, we have a paper by Parkin et al., ${ }^{17}$ also from the previous issue, about parental attitudes towards and beliefs about helmet use. Its strength is that it compares provinces with and without helmet legislation. Here, too, the findings seem predictable, with parents in provinces with helmet legislation more supportive of such legislation and of enforcement than those in non-legislation provinces. Perhaps surprising, however, is that all other attitudes and beliefs-concern about injury, belief in the effectiveness of helmets, rules about children always wearing a helmet and, most noteworthy, the belief that legislation decreases the amount of time their child spends cycling-are similar to those in "non-legislation" provinces.

It is reasonable to ask which comes first: parents with sensible bike safety attitudes or legislation that helps mould those attitudes? There are no data to help us answer this important question. It is often stated that legislation cannot be enacted until a certain level of public support is reached. What the magical threshold level is, or where studies supporting this view come from, is a mystery. Clearly it is politically much easier for a legislator to promote laws for which there is broad public support than the reverse. But there are many examples of enlightened legislation introduced with little such support. It seems likely that if public health authorities deem an issue serious enough to warrant legislation, eventually attitudes and beliefs will shift in that direction. Conversely, parents may ask how important it could be for their children to be helmeted if their province does not require that they do so.

Helmet law wars aside, how much has the larger bicycle safety picture changed in the last 25 years? Some statistics are encouraging. Although it remains uncertain where the credit belongs, bicycle injuries in Canada have greatly diminished over this period. ${ }^{18}$ Canadian Institute for Health Information (CIHI) data show that although "the annual number of cycling injury hospitalizations remained relatively stable between 2001-2002 and 2009-2010, the number of cycling-related head injuries decreased from 907 to $665 .{ }^{, 18 p 1}$ The report also notes that $78 \%$ of the admissions with severe head injury were not wearing a helmet at the time of the injury. ${ }^{18}$ However, helmets may have little effect on bicycling mortality. The Vehicular Cyclist ${ }^{19}$ cites Transport Canada data from 1975 to 2003 which it interprets as showing "no effect of increased helmet use among cyclists ... [on] prevailing fatality trends." However, it is evident from the data that helmet use increased and pedestrian and bicyclist deaths decreased over this time period by $42 \%$ and $39 \%$, respectively. The article chooses to attribute these declines to "general safety campaigns, such as those involving roadside breath-testing of motorists and speed surveillance using radar equipment,"19p1 implying that helmet use played no role. But these data don't mean helmets are ineffective; they may simply illustrate that a helmet is a poor match for a few thousand pounds of steel and that legislation without enforcement is meaningless.

With respect to the challenges I issued in 1989, have we progressed much or little? To be sure, we have better injury morbidity data thanks to CHIRPP and the National Ambulatory Care Reporting System (NACRS), but we remain almost as unresponsive to the findings as we were in 1989. Although several organizations have emerged to address the problem-the latest being Parachute (http://parachutecanada .org), an amalgam of Safe Kids Canada, SMARTRISK and Safe Communities-and some provinces are taking important preventive initiatives, ${ }^{20,21}$ injury prevention still sees far too little public health action in Canada.

\section{FIGURE 1}

The author, after being "doored" while cycling slowly on a quiet street

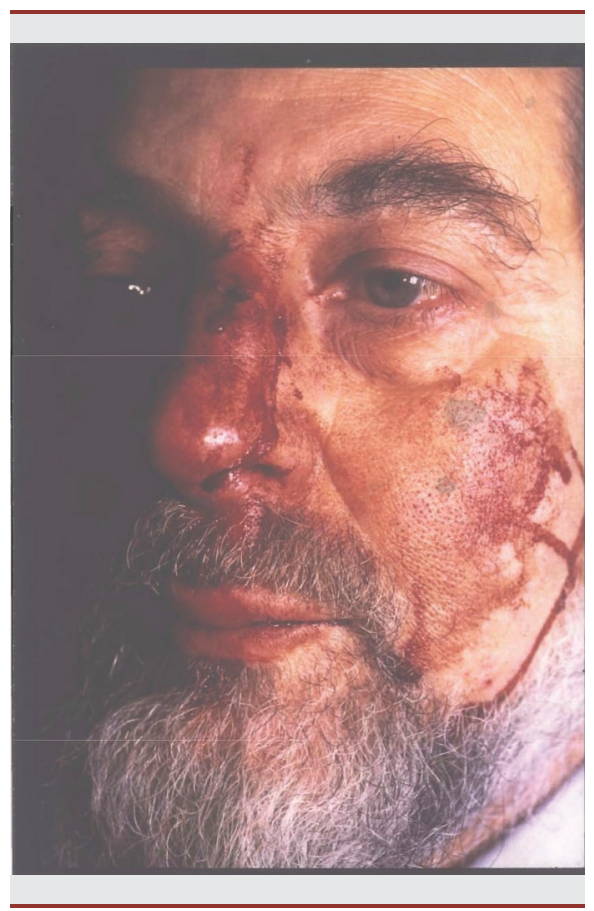


My 1989 editorial concluded: "Even if we had the best statistics, what is still lacking is a concerted effort to address this issue in the same aggressive manner as we have pursued the eradication of communicable diseases. For the most part the technology and much of the [knowledge] is there; what remains is for us to ... assemble the Canadian equivalent of Injury in America. With a few more resources and a solid commitment, Canada could be among the front-runners in the race to conquer injuries. If we choose otherwise, to mix the metaphor ... we will instead languish in the minor leagues for another decade-or more."1p2 I would only change what I wrote slightly, substituting the word quarter-century for the word decade.

\section{References}

1. Pless IB. Challenges for injury prevention: two neglected aspects. Chronic Dis Can. 1989:10(1):2 .

2. Thompson DC, Rivara FP, Thompson RS. Effectiviness of bicycle safety helmets in preventing head injuries: a case-control study. JAMA. 1996;276(24):1968-73.

3. Chong S, Poulos R, Olivier J, Watson WL, Grzebieta R. Relative injury severity among vulnerable non-motorised road users: comparative analysis of injury arising from bicycle-motor vehicle and bicycle-pedestrian collisions. Accid Anal Prev. 2010 Jan;42(1):290-6.

4. Walker I. Drivers overtaking bicyclists: objective data on the effects of riding position, helmet use, vehicle type and apparent gender. Accid Anal Prev. 2007;39;417-25.

5. Olivier J, Walter SR. Bicycle helmet wearing is not associated with close motor vehicle passing: a re-analysis of Walker, 2007 [online]. PLOS ONE. 2013;8(9):e75424 (doi:10.1371/journal.pone.0075424).

6. Walter SR, Olivier J, Churches T, Grzebieta R. The impact of compulsory cycle helmet legislation on cyclist head injuries in New South Wales, Australia. Accid Anal Prev. 2011;43(6):2064-71.
7. Olivier J, Walter SR, Grzebieta RH. Long term bicycle head injury trends for New South Wales, Australia following mandatory helmet legislation. Accid Anal Prev. 2013;50:1128-34.

8. Robinson D.L. Head injuries and bicycle helmet laws. Accid Anal Prev. 1996;28:46375 .

9. Pless IB. Are editors free from bias? The special case of letters to the editor. Inj Prev. 2006;12:353-4.

10. CanLII M.A. c. Stations de la Vallée de StSauveur inc., 2008 QCCS 240. Ottawa (ON): Canadian Legal Information Institute; 2008 Jan 31 [cited 2013 Mar 11]. Available from: http://canlii.ca/t/1vlg5

11. Chen A, Bushmeneva K, Zagorski B, Colantonio A, Parsons D, Wodchis WP. Direct cost associated with acquired brain injury in Ontario. BMC Neurol. 2012;12:76.

12. Miller TR, Zaloshnja E, Hendrie DV. Cost of traumatic brain injury and the return on helmet investment in the United States. In: Jallo J, Loftus CM, editors. Neurotrauma and critical care of the brain, New York: Thieme; 2009. p. 445-59.

13. Miller TR, Zaloshnja E, Lawrence BA, Crandall J, Ivarsson J, Finkelstein AE. Pedestrian and pedalcyclist injury costs in the United States by age and injury severity. Annu Proc Assoc Adv Automot Med. 2004;48:265-84.

14. Lindsay $\mathrm{H}$, Brussoni M. Injuries and helmet use related to non-motorized wheeled activities among pediatric patients. Chronic Dis Inj Can. 2013;34(2):74-81.

15. Mackenzie SG, Pless IB. CHIRPP: Canada's principal injury surveillance program. Inj Prev. 1999;5:208-21.

16. Romanow NR, Hagel BE, Williamson J, Rowe BH. Cyclist head and facial injury risk in relation to helmet fit: a case-control study. Chronic Dis Inj Can. 2013;34(1):1-7.

17. Parkin PC, DeGroot J, Macpherson A, Fuselli P, Macarthur C. Canadian parents' attitudes and beliefs about bicycle helmet legislation in provinces with and without legislation. Chronic Dis Inj Can. 2013;34(1): 8-11.
18. Canadian Institute for Health Information. Trauma registries: cycling injury hospitalizations in Canada, 2009-2010 [Internet]. Ottawa (ON): CIHI; 2011 Jul [cited 2013 Mar 11]. Available from: http://www .cihi.ca/CIHI-ext-portal/pdf/internet/INFO _CYCLING_INJURY_09-10_EN

19. The Vehicular Cyclist. Cyclist fatality trends in Canada: helmet effect undetectable in fatality trends [Internet]. 2007 Jun [cited 2013 Mar 11]. Available from: http:// www.vehicularcyclist.com/fatals.html

20. Government of British Columbia. Injury prevention initiatives [Internet]. Government of British Columbia [cited 2013 Nov 6]. Available from: http://www.health .gov.bc.ca/prevention/injuryinitiatives.html

21. Alberta Centre for Injury Control \& Research. Injury Control Alberta [online newsletter]. Available from: http://acicr .ca/learn-and-network/newsletters 